\title{
A Note on a Rare Case of Acephalic Monster.
}

\author{
By Axvie C. Gowdey, M.B. (Lond.), \\ Assistant Medical Superintendent, St. Pancras Infirmary (South), \\ Pancras Road, N.W.
}

The clinical history of the specimen is as follows. M.C., aged 21, single, was admitted in labour at 2 p.m., on May 4th, 1904 . The membranes had ruptured previous to admission, and according to the patient the liquor amnii had been in excess. On examination the os was partially dilated, the presenting part high and apparently vertex. At 6-40 p.m. she was delivered naturally of a female child weighing 5lbs. 7ozs. The presentation was vertex. The child was asphyxiated at birth, but soon revived. A few minutes later an acephalic female monster, weighing 3lbs. 3ozs. was spontaneously expelled, and with it the placenta, with both cords attached close together towards the edge. There was only one chorion. The accompanying photograph shows the appearance of the monster. It was absolutely devoid of even a rudimentary head, nor could any trace of a cranial bone be felt. At the upper end there was a circular line of hair with a central depression. The forearm was absent in the right upper limb, the hand, which possessed only three digits, being in contact with the lower end of the humerus. The left upper limb consisted of a very short humerus, a forearm, and hand with five digits. Talipes varus was markedly present in both feet. There were five toes on the right foot all webbed; the left foot had only three toes. On the abdominal end of the cord was a semitransparent cyst about the size of a large orange, through which a portion of the intestine could be seen and felt.

The surviving twin child had a soft, rounded, fluctuating swelling over the right parietal bone. It was covered by scalp, and was nonpulsating. There was no defect felt in the cranial bone beneath, nor did the tumour increase in size when the child cried. At first it was thought to be a caput succedaneum, but it did not diminish during the month the child was under observation.

The mother was a pale, somewhat nervous woman, who stuttered and became flurried when talking to strangers. She had had one child previously, a girl now aged five, who is healthy and in every way normal. The father of this child was not the father in the present case. 'There was nothing to note in the mother's family history; on the father's side there was a suspicion of tuberculosis. 


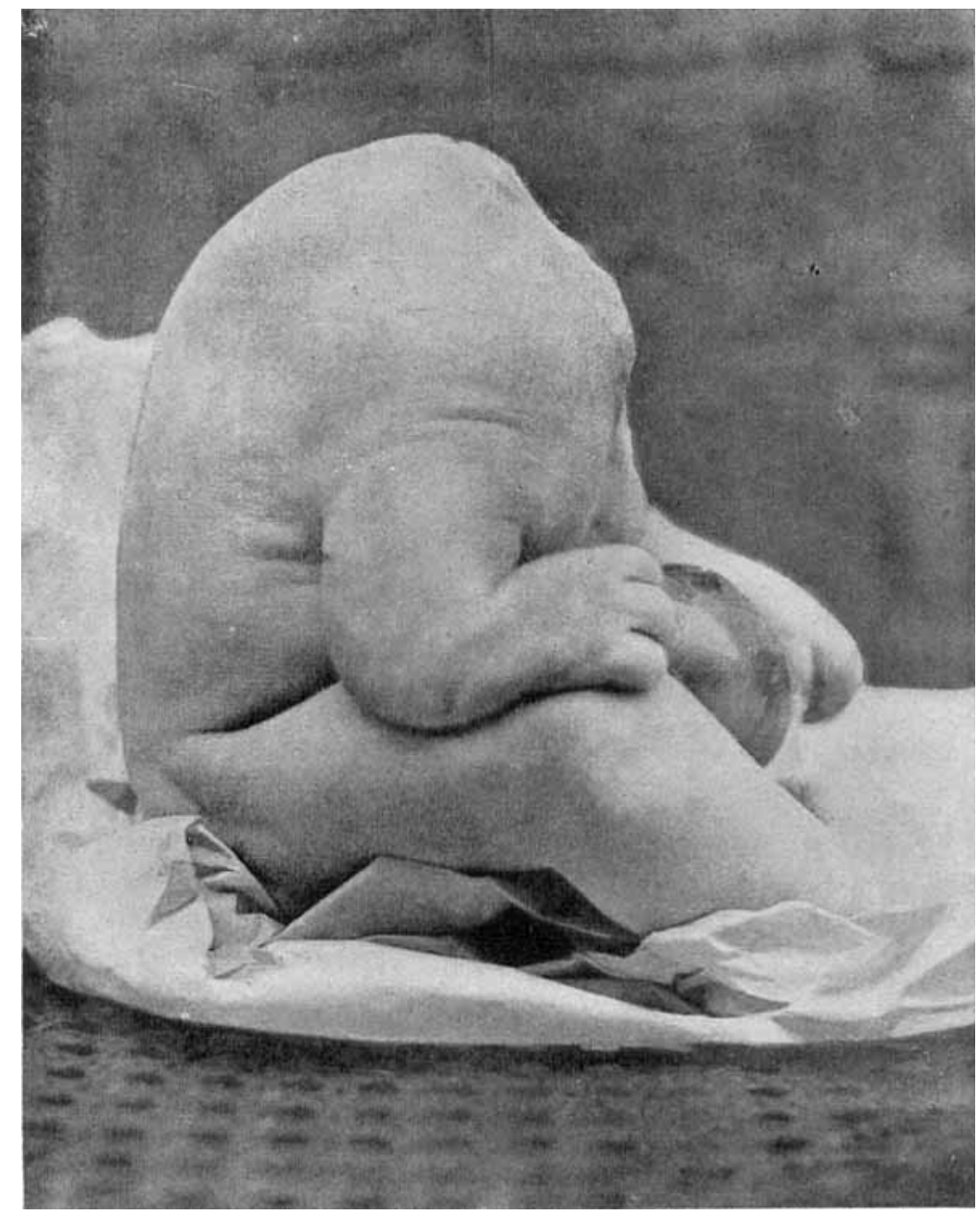



Remarks. Several cases of acephalic monster have been recorded. ${ }^{1}$ Of these three main types have been described. The acephalus monobrachius, in which there is one superior extremity. The paracephalus with no superior extremities, and the mylacephalus, which is a shapeless mass of flesh covered by skin. The present case is unique therefore in the possession of both upper limbs, although these were more or less defective. The omphalosites, of which acephalus is the commonest condition, are found in twin ova along with a normal fotus. Our case illustrates this. But occasionally anomalies of development occur in the more perfectly formed child. Such are cleft-palate, hare-lip, etc. In this instance there was only the swelling described on the head, which appeared to be nothing more than a cephalhæmatoma. The parasite, as in this case, is usually born last.

In acephalic monsters other deformities may exist besides the imperfect development of the superior extremities. Thus the heart may be absent, or rudimentary. In this case no dissection was made; the fact that the specimen was unique seemed sufficient to justify its preservation intact. Galabin ${ }^{2}$ and $\mathrm{Lusk}^{3}$ associate acephalic monsters with an acardiac condition, and explain the non-development of the head and upper limbs by an imperfect blood supply. Or the lungs and pelvic organs may be abnormal, and hernias are common. The abdominal swelling described in this case was of the nature of a hernia. As regards the sex, curiously enough acephalic monsters, like ours, are nearly all females. According to Ballantyne ${ }^{4}$ fotal malformations are associated with tubercle in the parents; it is interesting to note the suggestion of consumption in the father.

\section{References.}

1 Hirst and Piersol. "Human Monstrosities." Part iii., p. 137, and plates 25,26 , and 27.

2 Galabin. "A Manual of Midwifery," 6th edition, p. 276.

3 Lusk. "The Science and Art of Midwifery," p. 558.

4 Ballantyne. "Antenatal Pathology and Hygiene," Book ii., p. 215. 